\title{
ASPECTOS GENÉTICOS DA ESCOLIOSE IDIOPÁTICA DO ADOLESCENTE
}

\author{
GENETIC ASPECTS OF THE ADOLESCENT IDIOPATHIC SCOLIOSIS \\ ASPECTOS GENÉTICOS DE LA ESCOLIOSIS IDIOPÁTICA DEL ADOLESCENTE
}

Marcelo Wajchenberg ${ }^{1}$, Délıo Eulálio Martins², Eduardo Barros Puertas ${ }^{3}$

RESUMO

A escoliose idiopática do adolescente é uma doença frequente e sua etiologia permanece obscura. Várias hipóteses foram formuladas, entre elas a possibilidade da transmissão genética. Estudos na literatura procuraram analisar a prevalência da doença em determinadas populações, as possíveis formas de transmissão, a localização dos genes responsáveis e as variações de determinados genes (polimorfismos) que podem influenciar o desenvolvimento da deformidade. O objetivo deste artigo é revisar e atualizar os conceitos sobre a influência genética na etiologia da escoliose idiopática do adolescente.

Descritores: Genética; Escoliose/etiologia; Adolescente.

\begin{abstract}
The adolescent idiopathic scoliosis is a common disease and its etiology remains unclear. Several hypotheses have been devised, including the possibility of genetic transmission. Studies in the literature have examined the prevalence of the disease in certain populations, the possible modes of transmission, the location of genes and variations of certain genes (polymorphisms) that may influence the development of the deformity. This article intends to review and update the concepts of genetic influence in the etiology of adolescent idiopathic scoliosis.
\end{abstract}

Keywords: Genetics; Scoliosis/etiology; Adolescent.

\section{RESUMEN}

La escoliosis idiopática del adolescente es una enfermedad frecuente y su etiología continúa siendo obscura. Varias hipótesis fueron elaboradas, entre ellas, la posibilidad de la transmisión genética. Los estudios en la literatura procuraron analizar la prevalencia de la enfermedad en determinadas poblaciones, las posibles formas de transmisión, la localización de los genes responsables y las variaciones de genes específicos (polimorfismos) que pueden influenciar en el desarrollo de la deformidad. El objetivo de este artículo es revisar y actualizar los conceptos sobre la influencia genética en la etiología de la escoliosis idiopática del adolescente.

Descriptores: Genética; Escoliosis/etiología; Adolescente.

\section{INTRODUÇÃO}

Como definição, considera-se a escoliose idiopática como um desvio lateral na coluna vertebral, associado ao desvio rotacional em um indivíduo saudável, sem que haja uma causa conhecida. Esses indivíduos não apresentam distúrbios neurológicos, musculares ou outras doenças ${ }^{1}$. O estudo radiográfico não demonstra alterações vertebrais e apresenta curvas com mais de 10 graus, mensuradas pelo método de Cobb². A escoliose progride durante a fase de crescimento, podendo ser classificada em três categorias, de acordo com a idade em que a deformidade é notada, sendo infantil antes dos três anos, juvenil entre três e dez anos (ou início da puberdade) e do adolescente quando aparece após os dez anos ou após a puberdade ${ }^{3,4}$.

A etiologia da escoliose idiopática do adolescente permanece desconhecida. Em 1882 Adams não acreditava na existência de curvas fixas nos desvios laterais da coluna vertebral, propondo que primariamente haveria debilidade muscular com uma condição permissiva dos ligamentos ${ }^{5}$. Atualmente diferentes fatores têm sido sugeridos, como o desvio do padrão do cresci- mento, as alterações neuromusculares ou do tecido conjuntivo, o crescimento assimétrico dos membros e tronco, alterações da configuração sagital da coluna vertebral e fatores ligados ao meio ambiente $e^{4,6,7}$

\section{Estudos em gêmeos}

Desde 1875 são realizados estudos com gêmeos para tentar observar as influências dos fatores genéticos e do meio ambiente, na manifestação de certas doenças ${ }^{8}$. Fisher e George ${ }^{9}$ estudaram pares de gêmeos monozigóticos e dizigóticos com escoliose idiopática, avaliando a similaridade das deformidades e observaram que os aspectos ambientais foram capazes de modificar as características e gravidade da doença principalmente entre gêmeos dizigóticos. Kesling e Reinker ${ }^{10}$ relataram, em revisão sistemática, um índice de concordância de $73 \%$ em 37 pares de gêmeos monozigóticos e de $36 \%$ em 31 pares de gêmeos dizigóticos, comprovando maior similaridade entre gêmeos monozigóticos.

Recentemente Del Curto et al. ${ }^{11}$ apresentaram em seu trabalho um par de gêmeas monozigóticas, com escoliose idiopática do

1. Doutor em Ciências pela Universidade Federal de São Paulo e Professor Afiliado do Departamento de Ortopedia eTraumatologia da Universidade Federal de São Paulo - São Paulo, SP, Brasil.

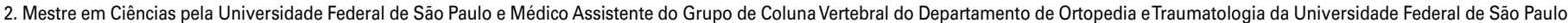
São Paulo, SP, Brasil.

3. Professor Associado, Livre Docente e Chefe do Grupo de Coluna Vertebral do Departamento de Ortopedia eTraumatologia da Universidade Federal de São Paulo - São Paulo, SP, Brasil.

Trabalho desenvolvido no Departamento de Ortopedia eTraumatologia da Universidade Federal de São Paulo, São Paulo, SP, Brasil.

Correspondência: Rua Borges Lagoa 783, 5ํandar. Vila Clementino, São Paulo. SP. Brasil. CEP 04038-031. E-mail: marcelow@einstein.br

Recebido em 19/06/2012, aceito em 31/07/2012. 
adolescente e curvas que divergiam quanto ao tipo, direção e gravidade, propondo que este fato ocorreria devido à influência do meio ambiente ou ação de fatores epigenéticos. Os fatores epigenéticos não estão relacionados com a sequência primária do DNA, existindo três mecanismos principais de alterações relacionados a este termo: metilação do DNA, modificação das histonas e ação de RNAs não codificadores ${ }^{11}$

\section{Prevalência e Modo de herança}

Em 1968 Wynne-Davies ${ }^{3}$ realizou estudo em 114 pacientes com escoliose idiopática para avaliar a incidência familiar desta doença e comparar com a população geral, para tentar encontrar alguma evidencia sobre a transmissão (genética) da doença. Neste estudo a autora relatou que $6,94 \%$ dos parentes de primeiro grau, 3,69\% dos parentes de segundo grau e 1,55\% dos parentes de terceiro grau eram afetados. Com estes resultados concluiu-se que há forte evidencia da relação dos fatores genéticos com a escoliose idiopática, havendo características sugestivas de um padrão de herança dominante ou poligênica.

Cowell et al. ${ }^{12}$ observaram em 110 famílias estudadas que $80 \%$ dos pacientes com escoliose idiopática do adolescente tinham outros membros afetados e sugeriram que o aparecimento de casos isolados de escoliose idiopática estaria relacionado a formas esporádicas decorrentes de novas mutações. Estes autores encontraram também alta prevalência (33\%) de familiares afetados em relação ao seu grupo controle da população geral $(5,6 \%)$. Czeizel et al. ${ }^{13}$ estudaram 116 famílias húngaras, e observaram ocorrência de escoliose idiopática do adolescente em $0,083( \pm 0,0037)$ dos parentes de primeiro grau, 0,02 $( \pm 0,0017)$ dos parentes de segundo grau e 0,0084 $( \pm 0,0007)$ dos parentes de terceiro grau.

Martim et al. ${ }^{14}$ observaram em uma população espanhola, que $25 \%$ dos pacientes investigados tinham um ou mais parentes afetados com escoliose idiopática em suas famílias, sendo que a prevalência observada em parentes de primeiro grau foi de 5,16\% e de $4,31 \%$ em parentes de segundo grau. Estes números foram similares aos encontrados por Wajchenberg et al. ${ }^{6}$ ao analisarem a genealogia de 100 famílias brasileiras, que tinham pelo menos um indivíduo com escoliose idiopática do adolescente, com curva maior ou igual a 20 graus. Estes autores notaram que 33 (33\%) tinham algum membro com a mesma doença, sendo 22 entre $422(5,21 \%)$ parentes em primeiro grau, 33 entre $727(4,54 \%)$ parentes em segundo grau e sete entre 78 (8,97\%) parentes de terceiro grau.

A prevalência da escoliose idiopática em estudos radiográficos, com populações escolares, variou entre 0,3\% a 15,3\%, porém quando se consideraram apenas curvas maiores do que dez graus, as taxas caíram para valores entre 1,5\% e 3\%. Em curvas maiores do que 20 graus, a prevalência ficou entre $0,3 \%$ e $0,5 \%$ e em curvas maiores do que 30 graus a taxa ficou entre $0,2 \%$ e $0,3 \%{ }^{4}$.

O padrão de herança para a transmissão da escoliose idiopática do adolescente ainda não é totalmente conhecido. Já foram

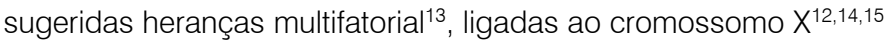
e autossômicas dominantes ${ }^{1,3,4,7,16-18}$. A análise de segregação, realizada por Axenovich et al. ${ }^{16}$ sugeriu que a escoliose idiopática é uma doença monogênica, em pacientes com curvas iguais ou maiores do que 11 graus $^{16}$. Sua pesquisa analisou as famílias de 101 indivíduos da cidade de Novosibirsk (Rússia), cuja idade variava entre sete e 18 anos.

\section{Estudos para localização de genes}

A partir de 2000 estudos de ligação genética, em famílias com múltiplos membros afetados, sugeriram possíveis regiões cromossômicas relacionadas à etiologia da escoliose idiopática do adolescente. Os estudos de ligação relacionam a recombinação entre duas estruturas genéticas, em um mesmo cromossomo, durante a meiose, na formação dos gametas. A idéia inicial de ligação gênica foi desenvolvida por Thomas Hunt Morgan, em 1910, ao aprimorar o raciocínio da segunda lei de Mendel, sobre a segregação independente, observada nas ervilhas. Para este raciocínio Morgan estudou dois genes autossômicos das drosófilas, relacionados à cor dos olhos e a estrutura das asas.

Utilizando esta técnica, Wise et al. ${ }^{17}$ em 2000, descreveram as primeiras regiões relacionadas a escoliose idiopática do adolescente, nos cromossomos $6 \mathrm{p}, 10 \mathrm{q}$ e 18q, ao estudar uma extensa família com sete membros afetados por esta doença.

Nos anos seguintes outros estudos familiares sugeriram que a escoliose idiopática do adolescente estivesse relacionada aos cromossomos $6,9,16$ e $17^{19}$ e às regiões cromossômicas $17 \mathrm{p} 11^{18,20}$, 19p13.3 $3^{7,21}$, Xq23 e Xq26.1 ${ }^{15}, 8 q 12^{22}, 9 q 31-q 34.2$ e 17q25.3-qtel ${ }^{1}$, $12 p^{23}$ e $18 q 12.1-12.2^{24}$. Em nosso meio Wajchenberg et al. ${ }^{25}$ não encontraram ligação ao estudar uma família do interior da Paraíba, com nove membros afetados.

A maior dúvida ao realizar estudos de ligação genética, para a escoliose idiopática do adolescente, ocorre ao indicar quais pacientes são afetados, pois a mensuração da curva, pelo método de Cobb, descrita em 1948 é dependente do examinador e pequenas variações na medida podem interferir na classificação do indivíduo como afetado ou normal. Desta forma indivíduos com uma diferença de apenas dois graus (um com nove e outro com 11 graus) são classificados de forma diferente.

Outra alternativa para estudos genéticos é a utilização de marcadores moleculares, previamente escolhidos e com posicionamento conhecido no genoma humano, como os SNPs ou snips, que são regiões cromossômicas "silenciosas", facilmente localizadas, sem repercussão fenotípica e que apresentam variabilidade de alelos heterozigotos. Autores como Aulisa et al. ${ }^{26}$, Quiu et $a l .{ }^{27}$ e Chen et al. ${ }^{28}$ realizaram estudos de polimorfismos genéticos para tentar relacionar a escoliose idiopática do adolescente com alterações em determinados genes.

Estatísticas atuais apontam que a escoliose idiopática do adolescente é responsável por 90\% dos casos de escoliose idiopática, atingindo mais de $2 \%$ da população pediátrica, proporcionando mais de 600.000 visitas médicas ao ano ${ }^{29}$. Devido a estes números foram realizados novos estudos, utilizando a técnica de microarray, em longas séries de indivíduos com escoliose idiopática do adolescente, possibilitando a descoberta de vários marcadores de polimorfismo em regiões cromossômicas, relacionadas não só a doença, mas também a sua progressão, por meio de uma escala de 1 a $200^{29}$

No entanto este método tem alto custo, foi desenvolvido somente para a população branca, não havendo validação para populações africanas e asiáticas ${ }^{19}$ e necessita maior comprovação na literatura mundial.

\section{CONSIDERAÇÕES FINAIS}

A escoliose idiopática do adolescente é uma doença doença relacionada a fatores genéticos, porém apesar de todos os estudos e tecnologia, ainda não foi possível descrever completamente a sua forma de herança e quais os genes responsáveis.

Os estudos familiares podem auxiliar na compreensão da doença, porém a grande dificuldade é rotular quais indivíduos são afetados, pois existe uma grande variabilidade na expressão da doença, sendo duvidoso considerar um indivíduo afetado apenas pela mensuração da deformidade pelo método de Cobb. Deve-se também considerar que determinados grupos são mais suscetíveis, como indivíduos do sexo feminino e caucasianos.

Provavelmente esta doença é poligênica, sofrendo influência de genes responsáveis pela síntese de proteínas importantes para a composição dos tecidos humanos, que agem na sustentação da coluna vertebral. Desta forma torna-se relevante o estudo do polimorfismo destes genes e da sua expressão nos tecidos que podem estar relacionados com a escoliose idiopática do adolescente. 


\section{REFERÊNCIAS}

1. Ocaka L, Zhao C, Reed JA, Ebenezer ND, Brice G, Morley T, et al. Assignment of two loci for autosomal dominant adolescent idiopathic scoliosis to chromosomes 9q31.2-q34.2 and 17q25.3-qtel. J Med Genet. 2008;45(2):87-92.

2. Cobb JR. Outline for the study of scoliosis. American Academy of Orthopaedic Surgeons Instructional Course Lectures. 1948;5:261-5.

3. Wynne-Davies R. Familial (idiopathic) scoliosis. A family survey. J Bone Joint Surg Br. 1968;50(1):24-30.

4. Lonstein JE. Adolescent idiopathic scoliosis. Lancet. 1994;344(8934):1407-12

5. Adams W. Lateral curvature of the spine, external characters and morbid anatomy (Lecture 4). Lectures on the pathology and treatment of lateral and other forms of curvature of the spine. London: Churchill; 1882.

6. Wajchenberg M, Puertas EB, Zatz M. Estudo da prevalência da escoliose idiopática do adolescente em pacientes brasileiros. Coluna. 2005; 4(3):127-31.

7. Alden KJ, Marosy B, Nzegwu N, Justice CM, Wilson AF, Miller NH. Idiopathic scoliosis: identification of candidate regions on chromosome 19p13. Spine (Phila Pa 1976). 2006:31(16):1815-9.

8. Galton F. The history of twins as a criterion of the relative posers of a nature and nuture. Pop Sci Monthly. 1875;8:345.

9. Fisher RL, George FV. A twin study of idiopathic scoliosis. Clin Orthop Relat Res. 1967; 55:117-26.

10. Kesling KL, Reinker KA. Scoliosis in twins. A meta-analysis of the literature and report of six cases. Spine (Phila Pa 1976). 1997;22(17):2009-14.

11. Del Curto D, Ueta RHS, Wajchenberg M, Martins Filho DE, Puertas EB Variações na apresentação fenotípica da escoliose idiopática do adolescente. Coluna. 2010;9(1):19-23.

12. Cowell HR, Hall JN, MacEwen GD. Genetic aspects of idiopathic scoliosis. A Nicholas Andry Award essay, 1970. Clin Orthop Relat Res. 1972;86:121-31.

13. Czeizel A, Bellyei A, Barta O, Magda T, Molnár L. Genetics of adolescent idiopathic scoliosis. J Med Genet. 1978;15(6):424-7.

14. Martín Martín J, Rodríguez Blanco C, Eguren Hernández EM, Díaz Polegre R, de León García F, Pedrosa Guerra Al. Family prevalence of idiopathic scoliosis. An Esp Pediatr. 1997; 46(2):148-50.

15. Justice CM, Miller NH, Marosy B, Zhang J, Wilson AF. Familial idiopathic scoliosis: evidence of an X-linked susceptibility locus. Spine (Phila Pa 1976). 2003;28(6):589-94.

16. Axenovich TI, Zaidman AM, Zorkoltseva IV, Tregubova IL, Borodin PM. Segregation analysis of idiopathic scoliosis: demonstration of a major gene effect. Am J Med Genet. 1999;86(4):389-94.
17. Wise CA, Barnes R, Gillum J, Herring JA, Bowcock AM, Lovett M. Localization of susceptibility to familial idiopathic scoliosis. Spine (Phila Pa 1976). 2000;25(18):2372-80.

18. Salehi LB, Mangino M, De Serio S, De Cicco D, Capon F Semprini S, et al. Assignment of a locus for autosomal dominant idiopathic scoliosis (IS) to human chromosome 17p11. Hum Genet. 2002;111(4-5):401-4.

19. Miller NH, Justice CM, Marosy B, Doheny KF, Pugh E, Zhang J, et al. Identification of candidate regions for familial idiopathic scoliosis. Spine (Phila Pa 1976). 2005;30(10):1181-7.

20. Clough M, Justice CM, Marosy B, Miller NH. Males with familial idiopathic scoliosis: a distinct phenotypic subgroup. Spine (Phila Pa 1976). 2010;35(2):162-8.

21. Chan V, Fong GC, Luk KD, Yip B, Lee MK, Wong MS, et al. A genetic locus for adolescent idiopathic scoliosis linked to chromosome 19p13.3. Am J Hum Genet. 2002; $71(2): 401-6$

22. Gao X, Gordon D, Zhang D, Browne R, Helms C, Gillum J, et al. CHD7 gene polymor phisms are associated with susceptibility to idiopathic scoliosis. Am J Hum Genet. 2007:80(5):957-65.

23. Raggio CL, Giampietro PF, Dobrin S, Zhao C, Dorshorst D, Ghebranious N, et al. A novel locus for adolescent idiopathic scoliosis on chromosome 12p. J Orthop Res. 2009;27(10):1366-72.

24. Gurnett CA, Alaee F, Bowcock A, Kruse L, Lenke LG, Bridwell KH, et al. Genetic linkage localizes an adolescent idiopathic scoliosis and pectus excavatum gene to chromosome 18 q. Spine (Phila Pa 1976). 2009;34(2):E94-100.

25. Wajchenberg M, Lazar M, Cavaçana N, Martins DE, Licinio L, Puertas EB, et al. Genetic aspects of adolescent idiopathic scoliosis in a family with multiple affected members: a research article. Scoliosis. 2010;5:7.

26. Aulisa L, Papaleo P, Pola E, Angelini F Aulisa AG, Tamburrelli FC, et al. Association between IL-6 and MMP-3 gene polymorphisms and adolescent idiopathic scoliosis: a casecontrol study. Spine (Phila Pa 1976). 2007;32(24):2700-2

27. Qiu XS, Tang NL, Yeung HY, Qiu Y, Cheng JC. Association study between adolescent idiopathic scoliosis and the DPP9 gene which is located in the candidate region identified by linkage analysis. Postgrad Med J. 2008;84(995):498-501.

28. Chen Z, Tang NL, Cao X, Qiao D, Yi L, Cheng JC, et al. Promoter polymorphism of matrilin-1 gene predisposes to adolescent idiopathic scoliosis in a Chinese population. Eur J Hum Genet. 2009:17(4):525-32.

29. Ogilvie J. Adolescent idiopathic scoliosis and genetic testing. Curr Opin Pediatr. 2010;22(1):67-70. 